\title{
The Development of Monitoring \& Management System for Environment Index of Ecological Engineering
}

\author{
Yan-Chyuan Shiau, Da-Jen Chu, Jen-Chen Jao, Chih-Kun Chu, Tsung-Pin Tsai and Miao-Ling Huang
}

\begin{abstract}
In order to maintain ecological environment, protect limited natural resources, promote the quality of life, and advance the eternally usage of all precious resources, we have some good achievement in both industrial circles, government official areas, and academic communities. Since each engineering method will cause different impact, we need to effectively grasp the biological information for engineers to make the appropriate decisions in choosing the construction system. In the completion time of the project, the ecological restoration condition can be an important indexes to determinate the successful of the ecological engineering method. In this research, we will use GIS, ER Model, Database and Delphi to develop "Ecological Engineering Environment Index Monitoring Management System". In this system, we will record the species, quantity, and appearing timing of all creatures. The referred index, such as gradient, vegetation multiplicity, landforms, etc., that can be used in design period will be stored and can be queried from system to achieve a better construction system. Through the help of this system, we can record all biological information and referred index so the engineering designer can inquire these data to exactly control the related ecological information around the project base. This will reduce the impact of the construction to the only earth we have. We can evaluate the restoration of the creatures to examine the effects of the project. These evaluation data can be used to adjust the design index for future project. We can then effectively protect the earth resources and make the better use of the natural resources.
\end{abstract}

Index Terms—Database, Ecological Engineering, ER Model, GIS

This work was supported in part by the National Science Council, Executive Yuan, Taiwan under Grant NSC 92-2622-E-216-022-CC3.

Yan-Chyuan Shiau is with the Department of Construction Engineering, Chung-Hua University, Hsin-Chu, 300 Taiwan (Tel: 886-3-5186689; Fax: 886-3-5378846; E-mail: ycshiau@ms22.hinet.net).

Da-Jen Chu is with the Department of Leisure and Recreational Management, Chung-Hua University, Hsin-Chu, 300 Taiwan (E-mail: tajen@chu.edu.tw).

Jen-Chen Jao is the graduate student of the Institute of Construction Management, Chung-Hua University, Hsin-Chu, 300 Taiwan (E-mail: m9216015@chu.edu.tw)

Chih-Kun Chu is with the Excellent Instrument \& Engineering Co. Ltd., Tu-Chen, Taipei, 236 Taiwan (E-mail: jack@excellent.com.tw)

Tsung-Pin Tsai is with the Construction Section, Chu-Nan Town Hall, Miao-Li, Taiwan (E-mail: winnie.bears@msa.hinet.net)

Miao-Ling Huang is the graduate student of the Institute of Construction Management, Chung-Hua University, Hsin-Chu, 300 Taiwan (E-mail: mlhuang2001@sinamail.com)

\section{ORIGIN AND OBJECTIVE}

$\mathrm{D}$ ifferent ecological engineering has different levels of impact to the environment, and the question of how to effectively control ecological data provides the opportunity for designers to select different technology and take correspondent measures during various administrations, as well as trying to minimize the influence from the project on the environment. Upon completion of the project, whether the pre-project ecological condition is recovered to the original state or not within the estimated time can also be an important index to evaluate the success of such ecological engineering.

At the moment, domestic ecological engineering is in the stage of experiment and promotion, information researched and collected by relevant units and experts are scattered in each unit and field without further integration; thus the unformatted level of ecological engineering is obviously reduced, which creates the problem of difficult information acquisition for relevant research personnel. The promotion of ecological engineering shall be suitably applied; thus this program has made further discussion towards the present state of development on domestic ecological engineering, and then collects information on domestic ecology. Each field is integrated to be a reference index for design of ecological engineering and in cooperation with GIS (Geographic Information System), the ER Model and database is used to establish the "Monitoring \& Managing System for Environmental Index of Ecological Engineering”. Besides integration on environmental information from the past, the module completed from database of this system can also be used as a reference for other projects during planning, design and construction.

\section{FUnCTIONAL REQUIREMENT}

The whole system of "Monitoring \& Managing System for Environmental Index of Ecological Engineering" includes the following items:

1. Build a basic information structure of the system and comply with the user's requirement.

2. At the present stage, the system uses current information of surrounding ecology on Check Dam of Shihmen Reservoir for establishment of information. 
3. Within the requirement on system development, three main groups were constructed, namely the System Operation, Basic Operation and Check Dam Operation.

4. The group of System Operation includes options such as maintenance on user's information, setting of parameters, setting of printer and exit. This group mainly sets the environment for the system.

5. The group of Basic Operation includes the type of Check Dam, name of river, working unit, fish species, type of bottom substrate, characteristics of water color, method of sampling and maintenance on name of County/City/Township. This group mainly constructs basic information for the ecological environment.

6. The group of Check Dam Operation includes information maintenance of Check Dam and information browsing of Check Dam, which are the center of this system.

7. In the information maintenance of Check Dam, body type of Check Dam, length $\mathrm{x}$ width $\mathrm{x}$ height, existence of fish ladder, description and current condition of environment are included on top of information on sub-items mentioned in basic operation.

8. The information browsing of Check Dam is another center of the system; it may combine the GIS graphic layers for functions such as positioning of Check Dam graphic layers, user's loading of graphic layers, search and modification.

\begin{tabular}{|c|c|}
\hline \multicolumn{2}{|c|}{$\begin{array}{c}\text { Table } 1 \\
\text { System module }\end{array}$} \\
\hline Operation groups & Operation items \\
\hline \multirow{4}{*}{ System Operation } & $\begin{array}{c}\begin{array}{c}\text { Maintenance of user's } \\
\text { information }\end{array} \\
\end{array}$ \\
\hline & Setting of parameters \\
\hline & Setting of printer \\
\hline & Exit \\
\hline \multirow{2}{*}{ Basic Operation } & Type of Check Dam \\
\hline & Name of river \\
\hline \multirow{6}{*}{ Basic Operation } & Working unit \\
\hline & Fish species \\
\hline & Type of bottom substrate \\
\hline & $\begin{array}{l}\text { Characteristics of water } \\
\text { color }\end{array}$ \\
\hline & Method of sampling \\
\hline & $\begin{array}{l}\text { Maintenance on name of } \\
\text { County / City / Township }\end{array}$ \\
\hline \multirow{2}{*}{ Check Dam Operation } & $\begin{array}{l}\text { Information maintenance of } \\
\text { Check Dam }\end{array}$ \\
\hline & $\begin{array}{l}\text { Information browsing of } \\
\text { Check Dam }\end{array}$ \\
\hline
\end{tabular}

\section{DiscuSSION ON SYSTEM STRUCTURE}

\section{A. System Analysis}

Through interviews of experts, this research collected relevant information on Check Dam of the water collecting area in Shihmen Reservoir. With messages provided by scholars, analysis was made on user's requirement, as well as discussion on the difference of the structure of relevant web sites, functional planning, and interface design and data analysis. The result obtained was used to analyze the direction of research and functional requirements for building the system. System analysis was used for execution of planning and design for the system structure. Consideration was given on system security, user's requirements and performance to be extended in the future for the stability, portability and expansibility of the system.

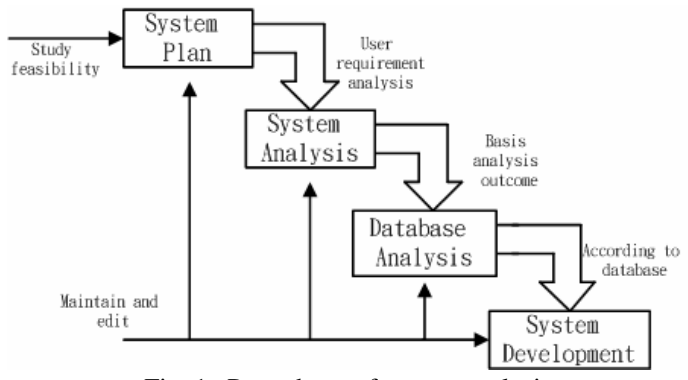

Fig. 1. Procedures of system analysis

\section{B. Structural Analysis of the Database}

The structure of the database is the core of the system, once mistakes occur on the structure of the database or the user's requirement is not complied with, mistakes will take place to the flow of the whole system and cause output of unexpected information. Therefore, to draft a structure of the database that complies with the functional requirement of the system is the key to the success of a project.

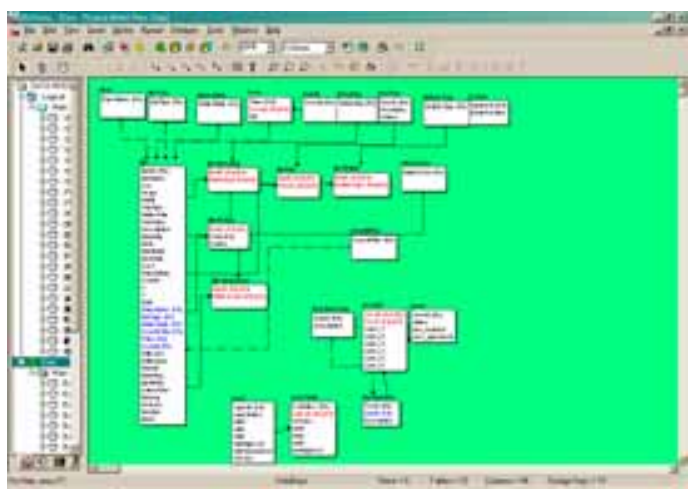

Fig. 2. Structure of database relationships

Along with advancing information technology, the database system has developed from the traditional "Relational Database" to an "Object-Oriented Database" (OODB). The OODB has become the mainstream of development on the database managing system. This research used the ER/Studio tool to build an ER Diagram, and then follow this model to plot the information procedure according to the user's requirement and build an E-R Model (Entity-Relationship Model). After the definition of the interactive relationships between columns and tables of each information table, the actual database is built, i.e. the database of actual relationships (as shown in Fig. 2).

After building the ER/Model, user may use tools provided by the software to transform the structure of database into Script File ( as shown in Fig. 3 ) readable by database managing system. The Database Console is allowed to read the data table 
of the system, columns in each data table, the property of each column, as well as the relationship between the Primary Key and Foreign Key of each data table to build the database of the system.

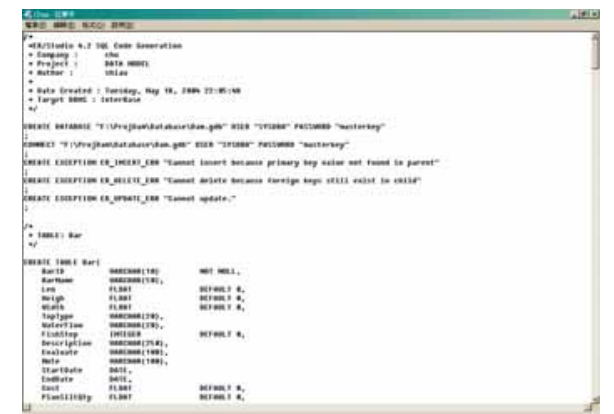

Fig. 3. Script File in database produced from ER/Studio

\section{Establishment of Relevant Information for Database}

Through analysis on the user's requirement, this research can clearly know what object the database shall build, where the content of the database is briefly described as follows:

(A) Basic information for ecological engineering:

a. Information of plants: group \& class, family name, Chinese name, Chinese nickname, altitude of distribution, distribution of plant group, remarks.

b. Information of animals: phylum, class, item, Chinese name, Chinese nickname, racial status, type of residence, figure characteristics, ecological habits, scientific name, place of origin, area of distribution, domestic area of administration distributed, altitude of distribution, remarks.

c. Information of main rivers: name of river, place or origin, length of mainstream, estuary and visual information.

d. Visual information: ID, category, index of database, picture title, picture description.

(B) Establishment of ecological index: included in GIS for building type of biological distribution, quantity and time of emergence in each area.

(C) Searching and printing of relevant information: all data built in the system can be searched; this includes cross searching of each column in each data table, searching for content, searching for the scope, complete match and partial match etc. The result of the search from the database is displayed on the screen and it can be saved as MS Word, Excel, or text file and printed.

(D) GIS information management

Geographically constructed information: filename, file description, coordinating system method of filing, types of symbol and data table corresponds with database system and remarks.

(E) Administration of database:

Add new system users: database administrator, name, password, authority, identity, contact number, contact address, E-Mail, Fax, work unit.

\section{Planning of System Structure \& Content of OPERATION}

The following section introduces the work group completed by this research:
A. System operation.
B. Basic operation.
C. Check Dam operation.

\section{A. System Operation}

The system operation module is divided into four pages: besides the basic setting for printer and exit, it includes maintenance on user's information (as shown in Fig. 4) and the setting of parameters (as shown in Fig. 5).

The maintenance on user's information can set six levels of authority for the user (enter, modify, add, print, delete and other); the setting of parameters can set displayed data and scale of graphic layer.

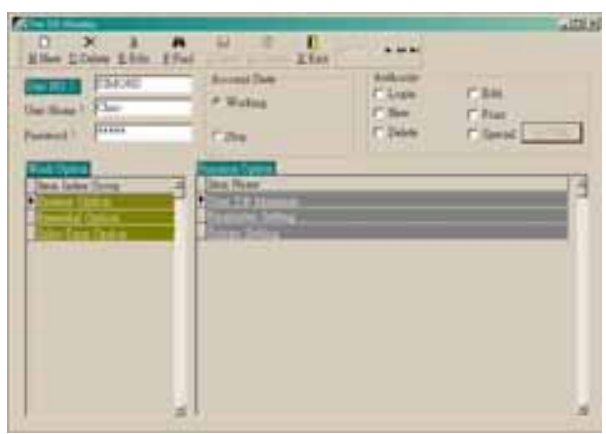

Fig. 4. Maintenance of user's information

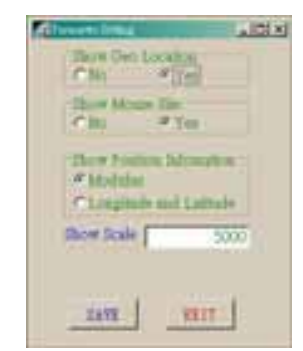

Fig. 5. Setting of parameters

\section{B. Basic Operation}

The basic operation includes type of Check Dam \& name of river (as shown in Fig. 6), work unit \& fish species (as shown in Fig. 7). In the water collecting area of Shihmen Reservoir, there are 11 types of Check Dam, 38 main rivers, 3 work units and pictures can be loaded for fish data as a reference. Furthermore, the type of bottom substrate \& characteristics of water color (as shown in Fig. 8), method of sampling \& name of County / City / Township (as shown in Fig. 9) are also available. There are 6 types of bottom substrate, 8 characteristics for water color and 4 sampling methods. 

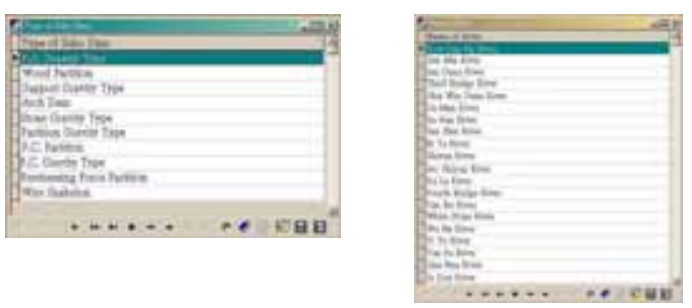

Fig. 6. Type of Check Dam \& name of river

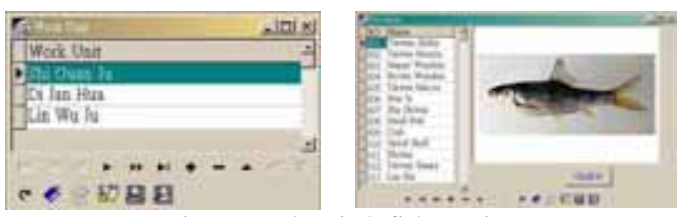

Fig. 7. Work unit \& fish species
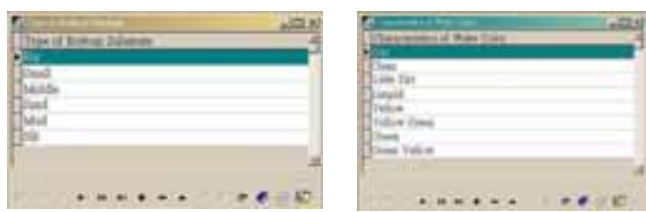

Fig. 8. Type of bottom substrate \& characteristics of water color
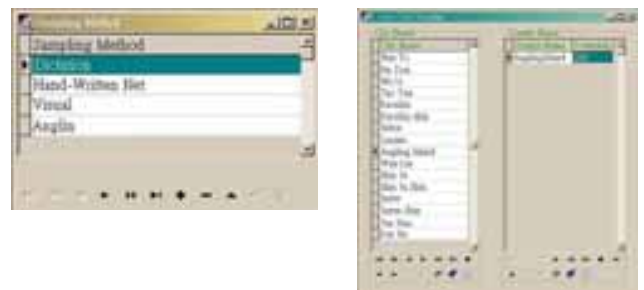

Fig. 9. Sampling method \& name of County / City / Township

For the control buttons, the description of each function in order is: $1^{\text {st }}$ item, previous 10 items, previous item, next item, next 10 items, last item, add, delete, modify, save, quit, renew, mark, move to, conditional filtering, search (Locate), search (Seek).

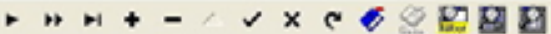

Fig. 10. Control buttons of the navigator

\section{Check Dam Operation}

The maintenance of Check Dam operation is shown in Fig. 11; besides function of add, delete and printing, the Check Dam includes information such as: number, name, type of dam body, County / City / Township located, river located, style, length, total height, top width of dam body, as well as existence of fish ladder, ecological evaluation and current state of environment etc.

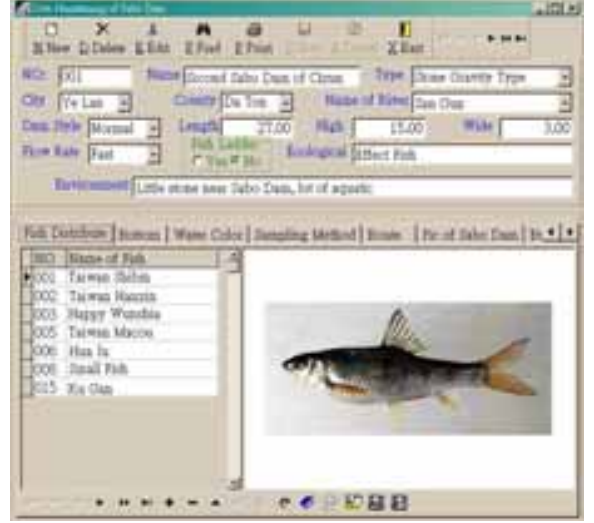

Fig. 11. Information maintenance on Check Dam

Each sub-page is described as follows:

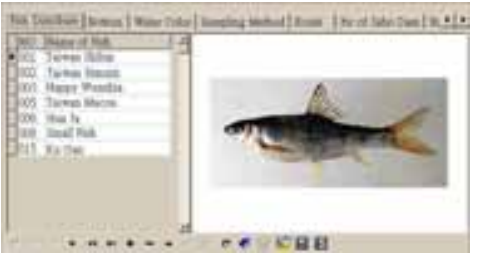

Fig. 11-1. Fish distribution

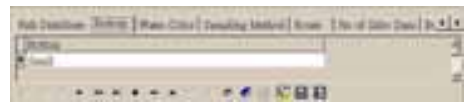

Fig. 11-2. Condition of bottom substrate

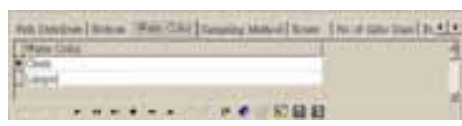

Fig. 11-3. Characteristic of water color

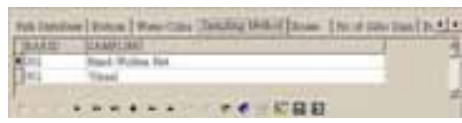

Fig. 11-4. Method of sampling

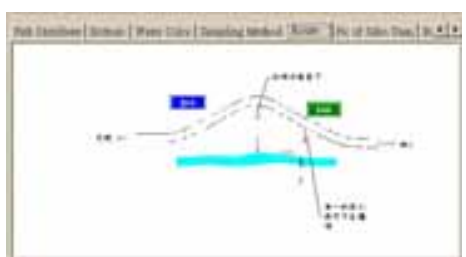

Fig. 11-5. Path
Information of fish distribution such as number, name and fish pictures.

The condition of bottom substrate is selected per data entered into the basic operation.

Similar to the condition of bottom substrate where selection is made per input value in the basic operation.

Option on the method of sampling for Check Dam.

Indication of path to reach this Check Dam. 


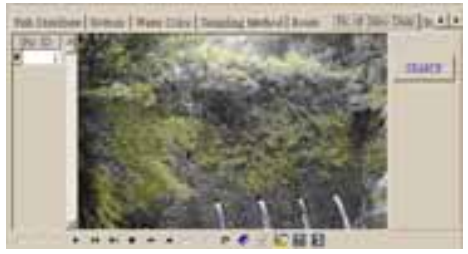

The picture of Check Dam can be saved to understand the current condition.

Fig. 11-6. Picture of Check Dam

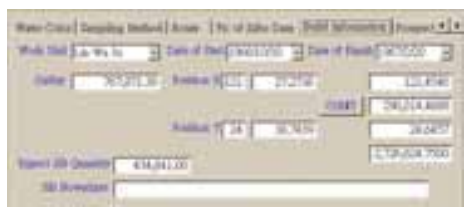

Fig. 11-7. Information of construction

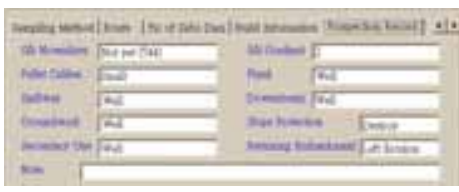

Fig. 11-8. Records of inspection

Inclusive of information such as work unit, date of commencement / completion, project cost, coordinates of the site, condition of deposit.

Including records such as condition of deposit, gradient, size of sand particles, condition of dam body, condition of bank damage.

\section{Browsing Operation on Check Dam}

Information browsing of Check Dam operation is shown as Fig. 12 below; the page combines with the GIS system and allows the user to read graphic layers. When the authority is sufficient, the edition of graphic layers can even be made. The functions are described as follows:

(A) Panel of control element:
a. open the graphic layer
b. enlarge the graphic layer
c. reduce the graphic layer
d. panning the graphic layer
e. full view
f. open database
g. word mark
h. select icon
i. set the scale and compass
j. move to the mouse cursor
k. set GPS connection
l. diagram of changing graphic layer
$\mathrm{m}$. restore cursor
n. word setting
o. produce graphic layer
p. read the graphic layer
q. move to point selected.

(B) Overview of graphic layer: the "open graphic layer" button on the element panel can be used to open the graphic layer. The order of the graphic layer can be adjusted via dragging. When the value of the basic setting of graphic layer is to be modified, left button of mouse can be double clicked on the graphic layer to enter the setting of graphic layers.

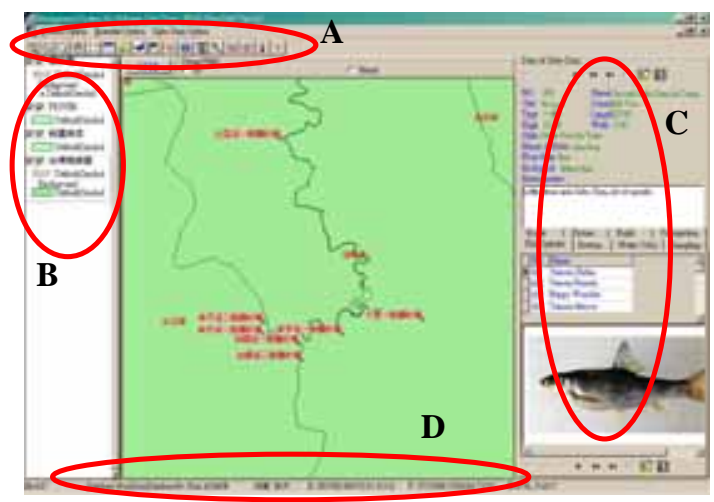

Fig. 12. Browsing Dialog of Check Dam

(C) Relevant information of Check Dam: the ecological condition of Check Dam can be searched here; if necessary, the panel of element control can even be moved to the point selected and centered.

(D) Geographical coordinates: including geographical coordinate axis, longitude and latitude moved by the mouse.

\section{CONCLUSION AND SUGgESTION}

\section{A. Conclusion}

This research is based on the ER Model, database and GIS, where Delphi is used as the main developing tool to build "Monitoring \& Managing System for Environmental Index of Ecological Engineering”. At present however, the construction is based on ecological information around Check Dam in water collecting area of Shihmen Reservoir, yet the Delphi software and GIS are originally a different system, so the compatibility on development is truly a difficult problem to solve. Luckily, with the assistance of supporting elements, the Delphi system may administrate and control the demonstration of GIS graphic layers, where the information of GIS graphic layers can interlink with information in the database and achieve the following performance:

From the result of this research, user can use the "Monitoring \& Managing System for Environmental Index of Ecological Engineering" to perform the above-mentioned integration of ecological information and obtain the following results:

(A) Establish the structure of the relevant ecological database per the user's requirement, as well as collecting ecological information around the Check Dam for Shihmen Reservoir, which is used to test the structure, connectivity and stability of the system.

(B) This system is a managing system that develops the combination of MIS and GIS interface, which makes no mistake on function of information connection and has a securing effect on the stability of the system.

(C) The system constructed by this research allows the user to browse graphic layers; if the user has sufficient authority, he may even edit the graphic layer according to his needs, as well as add, modify and search for relevant 
information.

\section{B. Contribution}

Through construction of the " Monitoring \& Managing System for Environmental Index of Ecological Engineering " , the following contributions can be made during execution of domestic ecological engineering:

(A) Convenient observation of ecological information on each area nationally can be made via this system.

(B) Function of the system can help working personnel to understand the change of the ecology, which will provide information for them to select the correct working method.

(C) With the integration and establishment of the basic system, manpower and time can be saved for the project to identify the ecological environment of the region, and identify the suitable method of construction.

(D) Through input of ecological information, country education can be combined; e.g. the local elementary school may perform some basic survey on local ecology to achieve ecological education by educating via entertainment.

\section{Suggestion}

Further research in the future for this research includes:

(A) The information included in the ecological environment were extensive and complicated. Since the species of animals and plants were numerous, and the information established in the database of this research was mainly constructed from the ecological situation of fish at the river base. Although the structure of the database was complete, it was rather lacking in informative value.

(B) This system integrated major directions required by each information; however, small details in the larger direction were still to be discussed among predecessors from various fields, so that a more practical and professional structure could be planned and expanded. For example, the system provided information of basic fish, but whether the detailed content of fish information satisfy the practical needs of personnel or not still remained unknown; therefore, future study and improvement was still to be expected.

(C) The system can further combine with PDA (Personal Digital Assistant) for connection and transmission of information, which is believed to be more convenient for user's operation.

\section{ACKNOWLEDGEMENT}

I would like to take this opportunity to show my appreciation to National Science Council, Executive Yuan, for its support of the study. Project No.: NSC 92-2622-E-216-022-CC3.

\section{REFERENCES}

[1] Weichang Chen, "Study on establishment of internet ecological engineering data system”, thesis for Master, Institute of Hydraulic \& Ocean Engineering in National Cheng Kung University, 2002.
[2] Administration office of Kinmen National Park, "Establishment of monitoring structure of ecological environment in Kinmen National Park", web site for research report:

http://www.kmnp.gov.tw/Research_P/Research/manage_cline/default.as

[3] Yirong Chen, "Feasibility of breeding firefly on Nongshui Rd. in Taipei suburb and study of its ecological engineering”, thesis for Master, Department \& Institute of Bioenvironmental Systems Engineering”, National Taiwan University, 2002.

[4] Wanting Hsu, "Discussion of space design criterion for urban canals taking Liuchia region for example”, thesis for Master, Master class from Department of Architecture and Urban Planning, Chunghua University, 2001.

[5] Shengjie Lin, "Summary for ecological breeding and application of Taiwanese rivers”, thesis for Master, Institute of Civil and Hydraulic Engineering, Feng Chia University, 2001.

[6] Wuhsiong Lin, "Technology of ecological engineering for stabilization of the river bed and protection of the river bank", thesis for Master, Institute of Civil and Hydraulic Engineering, Feng Chia University, 2001.

[7] Shujuan Wang, "Resource analysis of bird view during mid year in Sicao area of Tainan City and path the perpetual maintenance", thesis for Master, Department of Geography, National Kaohsiong Normal University, 2001。

[8] Mingda Lee, "Study on planning for administrating contaminated lakes with ecological engineering - taking Chungcheng Lake in Meinong for example”, thesis for Master, Institute for Marine Environment and Engineering, National Sun Yat-San University, 2001.

[9] Chikai Chuang, "Study on the history of development for environmental movement of ecological conservation for Datun River”, thesis for Master, Institute of Environmental Education, National Taiwan Normal University, 2001.

[10] Chengming Chou, "Establishment of evaluation procedure for ecological engineering on rivers - taking index of river condition as example", thesis for Master, Institute of Civil Engineering, National Taiwan University, 2001.

[11] Wunde Yu, Shaotsai Cheng and Wunching Lin, "Project management of ecological engineering”, Seminar on ecological engineering in water region, Water ecology environment research center in Chunghua University, 2001.01.

[12] Water Resources Office from Ministry of Economical Affairs, "Regulation for water activity and ecological engineering in water collecting area”, Department of Civil Engineering in National Taipei University of Technology, 2000.11. 